\title{
Does Purchasing Power Parity Hold for the German-US Real Exchange Rate? A Bayesian Dynamic Linear Model
}

\author{
Liping Zheng ${ }^{1}$ \\ ${ }^{1}$ College of Business and Public Administration, Drake University, Des Moines, USA \\ Correspondence: Liping Zheng, College of Business and Public Administration, Drake University, Des Moines, \\ IA, 50311, USA. Tel: 1-515-271-4160. E-mail: liping.zheng@drake.edu
}

Received: November 17, 2014

Accepted: November 25, 2014

Online Published: January 25, 2015

doi:10.5539/ijef.v7n2p20

URL: http://dx.doi.org/10.5539/ijef.v7n2p20

\begin{abstract}
In the purchasing power parity (PPP) literature, most studies do not take dynamics into account when they try to explain the deviation of PPP, and none use the Bayesian approach. This paper closes this gap by using the Bayesian dynamic linear model (DLM) to examine the German-US real exchange rate and test whether the Balassa-Samuelson effect explains the deviation from PPP. The results show that PPP does not hold during the period examined and the negative sign of the coefficient of German productivity differential between tradable and nontradable sectors and the positive effect of the productivity differential violate the assumption of the Balassa-Samuelson effect.
\end{abstract}

Keywords: PPP, exchange rate, Bayesian dynamic linear model, Blassa-Samuelson effect, productivity differential

\section{Introduction}

Purchasing power parity (PPP) is one of the most controversial topics in international economics. Froot and Rogoff (1995) gave a thorough literature review of what we know and do not know about PPP. They classified PPP tests into three periods. In stage one, people examined the relationship between the nominal exchange rate and price levels and tested whether beta equals one. The tests in the second period assumed that beta is the unit and tested the stationarity of the real exchange rate. In stage three, researchers used cointegration techniques to test a weaker version of PPP, a linear combination of prices and the nominal exchange rate.

However, empirically, PPP does not fit the data well. Many studies tried to explain this PPP deviation by including fundamental variables such as productivity and government spending. From the supply side, the Balassa-Samuelson effect provides a plausible explanation for the change in relative internal prices and thus the real exchange rate. Among those attempts, Hsieh (1982) was the first to examine the time series properties and confirmed the effect. Marston (1987) and Edison and Klovland (1987) also endorsed the effect. However, Froot and Rogoff (1991) and Asea and Mendoza (1994) showed that the effect is weak at the best. In addition to the mixed empirical results, as Froot and Rogoff (1995) pointed out, most of the studies did not include dynamics explicitly.

Researchers continued using panel data (e.g., Canzoneri et al., 1999; Koedijk et al., 1999; Chinn \& Johnson, 1997) and cointegration techniques (e.g., Bahmani-Oskooee \& Rhee, 1996; Dibooglu, 1996), and tried different models (e.g., Weber, 1997; SVAR model) to examine the determination of PPP from the supply side along with the Balassa-Samuelson effect tradition. In addition to the productivity differentials, Strauss and Ferris (1996) showed that the real wage gap between tradable and nontradable sectors may influence real exchange rates. Kakkar and Ogaki (1999) made the point that the relative price of nontradables and tradables does not necessarily move together with the real exchange rate because of different time periods, countries, and measures of relative prices.

In one of two more recent papers, De Carvalho (2002) presented a modified version of PPP and examined the yen-dollar rate over the years 1976-1991. He found that the increase in Japanese labor productivity is one cause of the appreciation of the yen. Chang (2002) introduced real wages in the estimation using the mean-squared error decomposition, and found that the real exchange rate and relative real wages are negatively related in the short run but positively related in the long run. 
Since Froot and Rogoff's 1995 paper, to the best of my knowledge, few studies have explicitly taken dynamics into account, and none used the Bayesian approach. The purpose of this paper is to close this gap in the PPP literature by using the Bayesian dynamic linear model (DLM) to examine the dynamics of the real exchange rate under the flexible exchange rate regime, and try to explain the deviation of the real exchange rate using the Balassa-Samuelson effect.

The major advantage of the DLM over other traditional static models is that it takes dynamics explicitly in the model. For static models, the quantitative relationship is globally applicable. In other words, the parameters are constant through time. However, this assumption is especially dangerous in time series analysis. As time passes, the value of the information will decrease, and thus, the parameters will change over time. This time-varying parameter or dynamics of the model is realized through the system equation in the DLM. In addition, the DLM is a linear model, which is simpler and easier to use than nonlinear models, but it captures the nonlinear relationship between the dependent and explanatory variables in a dynamic way. Since the process updates consistently, the relationship between any two adjacent points is linear. Another advantage of the model is that the retrospective analysis fits the data better by using all the information available, not only the information up to time $t$ but also all the information in the entire series. Moreover, the Bayesian approach takes external shocks in the analysis by adjusting the priors directly. By using probability distribution to represent knowledge about the parameters, the Bayesian approach makes the results easy to interpret. In addition, with robust priors, we get good results even from a small sample, which is always an issue in empirical macroeconomic analysis.

This paper uses quarterly data for the German real exchange rate from 1974:1 to 2001:1 and steady DLM to test whether (Consumer Price Index, CPI) PPP holds. Based on the result that (CPI) PPP did not hold during this period, this study continues using annual data (1984-2000) for German and American productivity in tradable and nontradable sectors and a regression DLM to investigate whether the Balassa-Samuelson effect can explain this deviation. The negative sign of the coefficient of German productivity differential between tradable and nontradable sectors and the positive effect of the productivity differential violate the assumption that productivity grows faster in tradable sectors.

The organization of the remainder of this paper is as follows. In the next section, the theoretical background of PPP and the Balassa-Samuelson effect is discussed. In Section 3, the Bayesian methodological framework is outlined. Data is presented in Section 4. In Section 5, the empirical results are presented, and the last section concludes.

\section{Theoretical Background}

The basic equation for PPP is

$$
Q=\frac{P}{S P^{*}}
$$

where $\mathrm{Q}$ is the real exchange rate; $\mathrm{P}$ is the domestic price level; $\mathrm{S}$ is the nominal exchange rate; and $\mathrm{P} *$ is the foreign price level. There are two versions of PPP: absolute and relative. Built on the law of one price (LOP), absolute PPP has the real exchange rate 1. Under relative PPP, Q is a constant. Balassa (1964) posited that to fully understand the PPP, nontraded goods should also be considered. Balassa (1964) and Samuelson (1964) argued that historically productivity in traded goods sectors grows faster than that of nontraded goods sectors. Because nontraded goods sectors are more labor intensive, the rise in productivity in the traded goods sectors will bid up the wage rate in the whole economy. As the result, the relative price of nontraded to traded goods and thus the CPI-based real exchange rate will increase. We can decompose the price level into two parts: the prices of tradables and nontradables. Specifically, suppose the overall price levels take the form

$$
\begin{aligned}
& P=P_{T}^{\gamma} P_{N T}^{1-\gamma}, \\
& P^{*}=P_{T}^{* \gamma} P_{N T}^{* 1-\gamma}
\end{aligned}
$$

where $P_{T}$ is the domestic price level of the tradables and $P N_{T}$ is the price level of the nontradables. Foreign country is denoted with "*".

To test the PPP and examine the Balassa-Samuelson effect, it is useful to substitute equation (2) into equation (1) and take the logarithm form, which gives

If we assume the price of the tradables is 1 , then

$$
q_{t}=p_{t}-p_{t}^{*}-s_{t}=\gamma\left(p_{T}-p_{T}^{*}\right)+(1-\gamma)\left(p_{N T}-p_{N T}^{*}\right)-s_{t} .
$$




$$
q_{t}=p_{t}-p_{t}^{*}-s_{t}=(1-\gamma)\left(p_{N T}-p_{N T}^{*}\right)-s_{t} .
$$

With the Cobb-Douglas production functions for traded and nontraded goods, we have

$$
p_{N T}=\frac{\mu_{L N}}{\mu_{L T}} \alpha_{T}-\alpha_{N T}, p^{*}{ }_{N T}=\frac{\mu^{*}{ }_{L N}}{\mu^{*}{ }_{L T}} \alpha_{T}^{*}-\alpha_{N T}^{*},
$$

where $\mu_{L}$ is the labor share of income in the sector and $\alpha$ is the log of the productivity of the sector. Assuming the labor shares of the income are the same for domestic and foreign countries, we then have

$$
q_{t}=p_{t}-p_{t}^{*}-s_{t}=(1-\gamma)\left[\frac{\mu_{L N}}{\mu_{L T}}\left(\alpha_{T}-\alpha_{T}^{*}\right)-\left(\alpha_{N T}-\alpha_{N T}^{*}\right)\right]-s_{t} .
$$

If $\frac{\mu_{L N}}{\mu_{L T}}>1$, that is, if the nontraded goods sectors are more labor intensive, then an increase in productivity in domestic traded goods will lead to an increase in the domestic relative price of nontraded goods, and thus the real exchange rate.

\section{Methodological Framework}

In this study, the most general model with regressors is as follows:

$$
\begin{aligned}
q_{t}=p_{t}-p_{t}^{*}-s_{t} & =\bar{q}_{t}+\beta_{1}\left(\alpha_{t}^{T}-\alpha_{t}^{N T}\right)+\beta_{2}\left(\alpha_{t}^{* T}-\alpha_{t}^{* N T}\right)+v_{t}, & & v_{t} \sim N\left(0, V_{t}\right), \\
\bar{q}_{t} & =\bar{q}_{t-1}+w_{1 t}, & & w_{1 t} \sim N\left(0, W_{1 t}\right), \\
\beta_{1 t} & =\beta_{1 t-1}+w_{2 t}, & & w_{2 t} \sim N\left(0, W_{2 t}\right), \\
\beta_{2 t} & =\beta_{2 t-1}+w_{3 t}, & & w_{3 t} \sim N\left(0, W_{3 t}\right) .
\end{aligned}
$$

With the notation from the DLM framework, the response, regression vector, and system matrix are defined as:

$$
\begin{gathered}
Y_{t}=q_{t}, \\
F_{t}=\left(\begin{array}{l}
1 \\
\alpha_{t}^{T}-\alpha_{t}^{N T} \\
\alpha_{t}^{{ }^{* T}}-\alpha_{t}^{*_{N T}}
\end{array}\right), G_{t}=\left(\begin{array}{lll}
1 & 0 & 0 \\
0 & 1 & 0 \\
0 & 0 & 1
\end{array}\right), \theta_{t}=\left(\begin{array}{l}
\bar{q}_{t} \\
\beta_{1 t} \\
\beta_{2 t}
\end{array}\right) .
\end{gathered}
$$

Using the framework and notation developed by Pole et al. (1994), we can write the DLM as

$$
\begin{aligned}
\text { Observation Equation: } Y_{t}=F_{t}^{\prime} \theta_{t}+v_{t}, & v_{t} \sim N\left(0, V_{t}\right), \\
\text { System Equation: } \theta_{t}=G_{t} \theta_{t-1}+w_{t}, & w_{t} \sim N\left(0, W_{t}\right),
\end{aligned}
$$

Where $Y_{t}$ is the observation series at time $\mathrm{t}$; $\mathrm{Ft}$ is the regression vector; $\theta \mathrm{t}$ denotes the vector of unknown parameters; $v_{t}$ is white noise with zero mean and variance $v_{t}$ and is normally distributed; $G_{t}$ is a matrix of the known coefficients that determine how the state vectors evolve systematically over time; and $w_{t}$ is white noise with zero mean and covariance matrix $w_{t}$ is normally distributed.

Theoretically, it is assumed that variances V and $\mathrm{W}$ are known. However, in empirical analysis, they are not. The Bayesian approach deals with this problem by using the information-discounting factor, which is between zero and one. The idea is very simple: The farther away the information is from today, the less useful the information is for forming a future forecast. For example, a discount factor at 0.95 means that $5 \%$ of the information today will be lost tomorrow. In the DLM, this process is modeled through the system equation. When time passes, the uncertainty will increase, and thus, the variance will become larger. Then the key problem is choosing an appropriate discount factor. In practice, we choose the discount factor with the best forecast performance among a set of discount values.

After a model is selected, the first step for researchers is to form their priors, that is, to quantify their knowledge and assumptions in terms of the probability distribution. The DLM assumes normality; therefore, the mean and variance are enough to characterize the distribution. These priors, combined with information from the data, will yield the posterior distribution at time $t$ using the Bayes' theorem. We then have 


$$
p\left(\theta_{t} \mid D_{t-1}, y_{t}\right)=\frac{p\left(Y_{t}=y_{t} \mid \theta_{t}, V_{t}\right) p\left(\theta_{t} \mid D_{t-1}\right)}{p\left(Y_{t}=y_{t}\right)}
$$

where $D_{t}$ is information up to and including time $\mathrm{t} ; p\left(\theta_{t} \mid D_{t-1}\right)$ is the prior related to a view of the parameter distribution at time $\mathrm{t}$ given the information up to time $t-1 ; p\left(Y_{t}=y_{t} \mid \theta_{t}, V_{t}\right)$ is the likelihood function at time $t$ the joint distribution of the data given the model specifications; $p\left(\theta_{t} \mid D_{t-1}, y_{t}\right)$ is the posterior; and $p\left(Y_{t}=y_{t}\right)$ is the information we have at time $t$. Note that $p\left(Y_{t}=y_{t}\right)$ is not a function of $\theta t$ but a constant that normalizes the density function. Typically, the normalizing term is ignored, and the posterior is proportional to the prior and the likelihood

$$
\text { posterior } \propto \text { likelihood } \times \text { prior. }
$$

This Bayesian learning process is the mechanism though which we can modify our uncertainty about the future when new information is available. One of the major advantages of the Bayesian methodology is that it incorporates new external information into the prior and thus into the formulation of the posterior.

The goal of Bayesian analysis is to obtain the parameter distribution conditional on all the information and beliefs. During the process from prior to posterior, observations with low probability may occur from unusual circumstances. We should be aware of those circumstances and decide how we should deal with them considering whether the "shock" is profound or not. We may want to adjust the model to produce more accurate forecasts. This monitoring process is part of the assessment of model specification and will be repeated whenever there is a sign of departure from the current model.

In addition to forward-looking processes, we can also start analysis from the end of the period and use all the information available to better understand the development of the time series. For example, our data set of the German real exchange rate spans 1974:1 to 2001:4. When we estimate the level of the real exchange rate of 1984:3 backwards, we take into account all the information not only up to and including 1984:3 but also include the data from 1984:4 until 2001:4. This backward-looking process is also called smoothing or retrospective analysis.

\section{Data}

The quarterly German mark and U.S. dollar exchange rates and CPIs spanning 1974:1 to 2001:4 come from International Financial Statistics published by the International Monetary Fund (IMF).

To test the Balassa-Samuelson effect, the productivity data is not available, and it is constructed from the ratio of production to employment. Because construction employment data is not available for (Western) Germany before 1983, the data used to test the effect is from 1984 to 2000.

The primary production data comes from the International Sectoral Database (ISDB), which was published by the OECD. The data set is no longer published. The existing database includes annual data about value-added production, employment, and factor returns for 14 countries (Note 1) and 20 sectors (Note 2) from 1960 to 1997. The German production data from 1984 to 1990 is from the ISDB, and the data from 1991 to 2000 is from the OECD STAN Database for Industrial Analysis. The employment data from 1991 to 2000 for Germany is from STAN, and the employment data from 1984 to 1990 is calculated from the Structural Statistics for Industry \& Services-Industry Survey, Economic Accounts for Agriculture, and the Main Industrial Indicators (Note 3).

The American production data from 1984 to 1993 is from the ISDB. The production data from 1994 to 2000 and the employment data are from the STAN.

Following the classification by De Gregorio et al. (1994), agriculture, mining, all manufacturing, and transportation aredefined as tradables and other sectors are non-tradables. Then the productivity in the traded and nontraded goods sectors is calculated by the ratio of production to employment.

\section{Results}

Using the DLM framework, this study starts with the steady model of the German real exchange rate and then adds productivity differentials to the model to test the Balassa-Samuelson effect.

\subsection{Steady Model of the Real Exchange Rate}

The steady model of the real exchange rate can be written as 


$$
\begin{array}{ll}
q_{t}=\bar{q}_{t}+v_{t}, & v_{t} \sim N\left(0, V_{t}\right) \\
\bar{q}_{t}=\bar{q}_{t-1}+w_{t}, & w_{t} \sim N\left(0, W_{t}\right)
\end{array}
$$

In the general DLM notation, $\theta_{t}=\bar{q}_{t}$, the steady model has only the underlying level without other explanations. The regression vector Ft and system matrix Gt are at the constant value 1. The model asserts that the level, $\bar{q}_{t}$, remains roughly constant over a short period of time but may wander in a random way in the long run. This shows that if the level is not stable over time, then the PPP does not hold.

Figure 1 shows the time plots of German real and nominal exchange rates from 1974:1 to 2001:4. The real exchange rate series has a roughly downward trend with a sharp decrease around 1985.

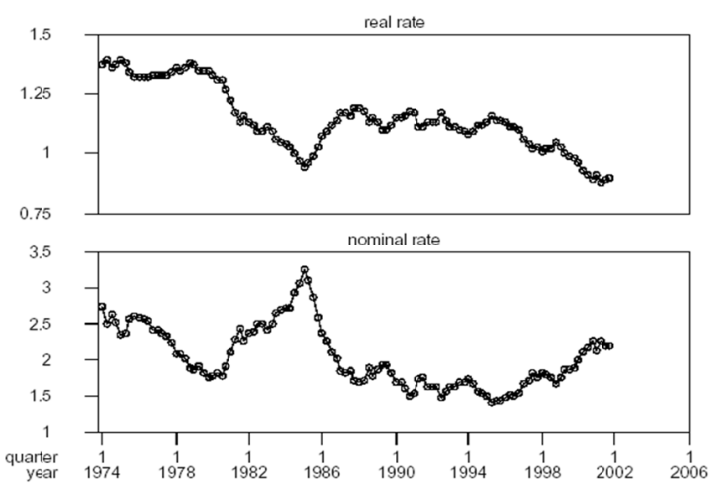

Figure 1. German real and nominal exchange rates

Note. With Respect to US Dollars (1974:1-2001:4).

Before we start Bayesian analysis, we first set our priors. The initial priors are given in Table 1 with mean 1 and standard deviation 0.2 for the trend, which represent large prior uncertainty. We want to select priors from which we can construct a $95 \%$ confidence interval (e.g., $[0.6,1.4]$ in this case) that encompasses the entire range of the real exchange rate series.

Table 1. Initial prior setting - Steady model

\begin{tabular}{ccc}
\hline Component & Mean & Std. Dev \\
\hline $\bar{q}$ & 1 & 0.2 \\
\hline
\end{tabular}

Note. Observation std. Dev estimate is 1 . Degree of freedom is 1.

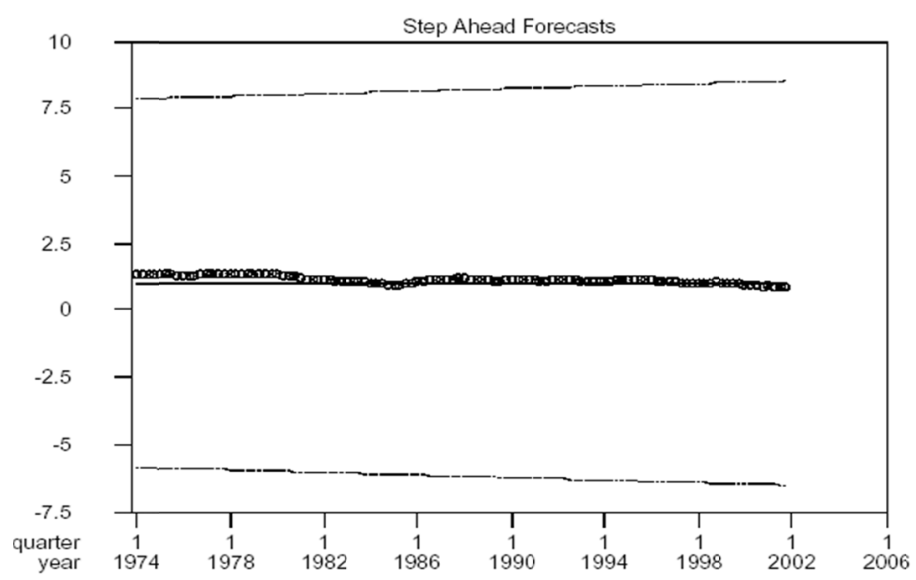

Figure 2. One quarter ahead forecasts for the Steady model

Note. with specific priors. 
Figure 2 shows the one-quarter ahead forecasts with a forecast horizon from 1974:1 to 2001:4. The dotted line is the observation series, the real exchange rate. The line in the middle is the forecast mean. The other two lines are the $90 \%$ uncertainty limits about the forecast mean. The values of the real exchange rate are very close to the predicted mean, but the uncertainty is huge. The forecast means are constant at one - the prior mean for the level. Notice the uncertain limits diverge over time. This is exactly the dynamic nature of the model: The uncertainty increases as time passes. Remember we start our forecasts from the beginning of the period and lose information as we move forward.

In the dynamic analysis, the information loss can be realized by the discount factors. We choose the best discount factor by comparing the forecasts results for a set of discount factors. The forecast performance summary is reported in Table 2. In the steady model, there is only one trend discount factor. The best values for measure are those with a trend discount around 0.8. Table 3 shows another set of forecast summary statistics with intervention, and the best discount is 0.8 . This time the analyses were performed with BATS (Note 4) level decrease monitor on, which means we make use of the downward shift in the trends. Comparing the measures in Table 2 and Table 3, the measures are generally improved with intervention. From 1981:2, analyses were subject to monitor warning signs and corrected by the BATS default action. Because the run length is greater than one, the observations were not considered outliers and then ignored but treated as a tendency. With use of the downward shift in the trends, Figure 3 to Figure 5 show the results of dynamic analysis with a trend discount factor 0.8 and observation variance discount factor 0.99 .

Table 2. Forecast performance summary - Steady model

\begin{tabular}{cccc}
\hline Trend Component Discount & MSE & MAD & Loglik \\
\hline 0.80 & 0.0263 & $0.0409^{*}$ & $171.5100^{*}$ \\
0.85 & $0.0035^{*}$ & 0.0465 & 155.1200 \\
0.88 & 0.0044 & 0.0508 & 143.4300 \\
0.89 & 0.0047 & 0.0524 & 139.1600 \\
0.90 & 0.0051 & 0.0540 & 134.6800 \\
0.95 & 0.0083 & 0.0656 & 108.0200 \\
0.98 & 0.0128 & 0.0830 & 84.5110 \\
0.99 & 0.0154 & 0.0943 & 74.4830 \\
1.00 & 0.0188 & 0.1079 & 63.7470 \\
\hline
\end{tabular}

Note. MSE is Mean Squared Error. MAD isMean Absolute Deviation. Loglik is Log Predictive Likelihood.

* denotes best value for measure. Observation variance discount is 0.99 .

Table 3. Forecast performance summary with intervention - Steady model

\begin{tabular}{cccc}
\hline Trend Component Discount & MSE & MAD & Loglik \\
\hline 0.80 & $0.0022^{*}$ & $0.0370^{*}$ & $183.9900^{*}$ \\
0.85 & 0.0027 & 0.0410 & 171.9100 \\
0.88 & 0.0031 & 0.0044 & 163.3500 \\
0.89 & 0.0031 & 0.0451 & 160.2000 \\
0.90 & 0.0035 & 0.0464 & 156.8900 \\
0.95 & 0.0050 & 0.0544 & 137.7800 \\
0.98 & 0.0063 & 0.0598 & 125.0500 \\
0.99 & 0.0068 & 0.0616 & 120.7800 \\
1.00 & 0.0074 & 0.0633 & 116.3900 \\
\hline
\end{tabular}

Note. MSE is Mean Squared Error. MAD isMean Absolute Deviation. Loglik is Log Predictive Likihood.

*denotes best value for measure. Observation variance discount is 0.99 .

Figure 3 is the one-step forecast of the German real exchange rate, which includes information up to time $t-1$. In this one-step analysis, assume we have no priors about the data, and let BATS determine the start value after the software examines the series. The forecasts are consistently high from the late 1970s to 1986 and in the late 1990s but consistently low in the late 1980s. The point forecasts miss some of the series structure. The missing structure is confirmed in Figure 6, which indicates a strongly nonrandom autocorrelation pattern in the forecasts residuals. Positive autocorrelation in residuals is typically an indication of insufficient dynamic movement in the 
component parameter; that is, the discount factors are high. But the uncertainty around the online fitted values (online estimated levels) (Note 5) (Figure 4), the model's best estimate of the current quarterly real exchange rate, since the data up to and including this quarter's observed value, $\mathrm{E}\left[\bar{q}_{t} \mid D_{t}\right]$, is small, which is consistent with the high discount factor. This shows that the model is probably appropriate. Figure 5 shows the plots of the retrospective analysis, which incorporates all the information in the series. We can see that the real exchange rate is not constant or stable within the $90 \%$ confidence interval, showing that (CPI) PPP does not hold during the entire period. However, the real exchange rate is relatively stable within a short period even though the rate wanders away over time. This suggests that underlying factors account for the movement of the price levels.

In the next section, the productivity differentials between tradables and nontradables of Germany and the US are added to the steady model to test whether the Balassa-Samuelson effect can explain why the (CPI) PPP in this period does not hold.

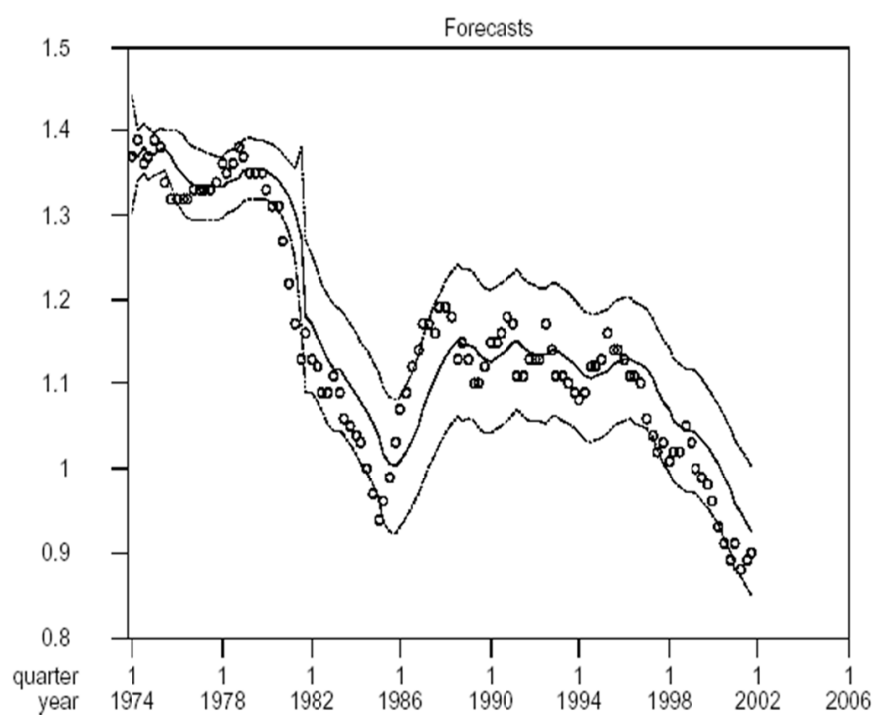

Figure 3. One step forecasts for the German real exchange rate

Note. with BATS selected priors.

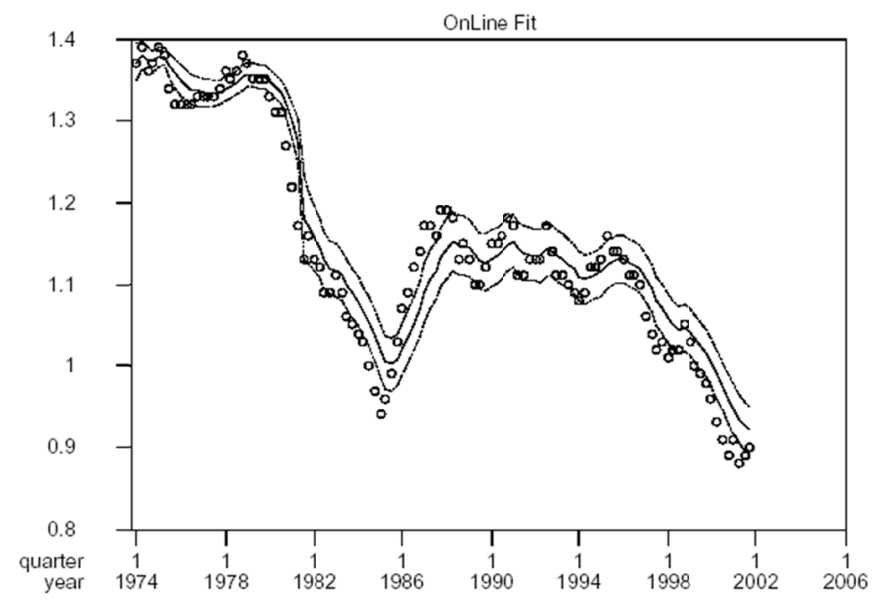

Figure 4. On-line fitted value (on-line estimated level) for German real exchange rate 


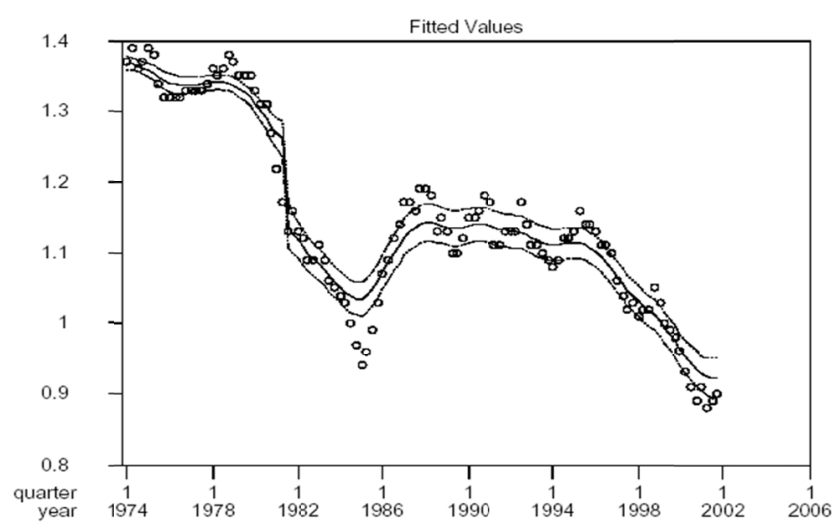

Figure 5. Retrospective fitted German real exchange rate

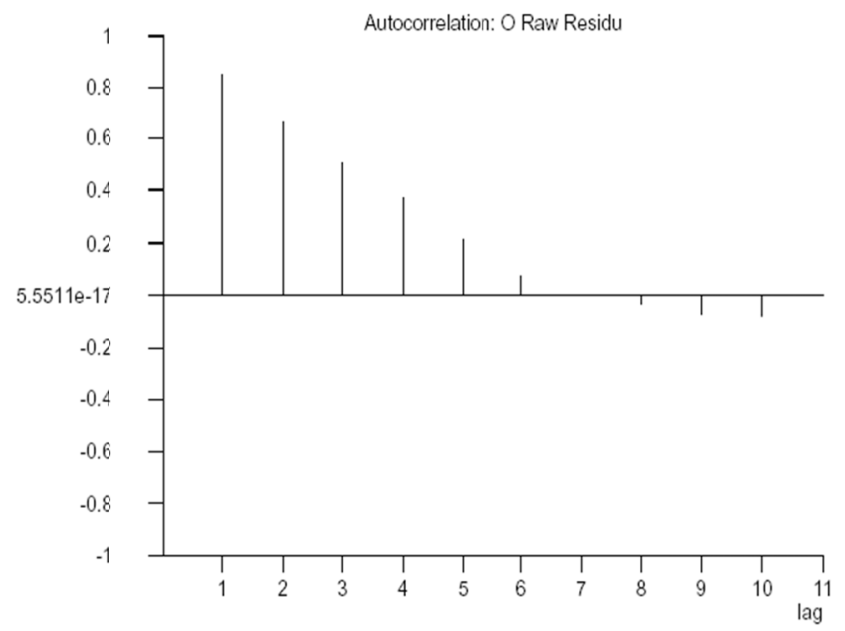

Figure 6. Autocorrelation of on-line fitted residuals

\subsection{Regression Model with Productivity Differentials}

The model we investigate here is a two-component model in which the components are a level and a two-variable regression with all terms in logarithms:

$$
\begin{aligned}
q_{t}=p_{t}-p_{t}^{*}-s_{t} & =\bar{q}_{t}+\beta_{1}\left(\alpha_{t}^{T}-\alpha_{t}^{N T}\right)+\beta_{2}\left(\alpha_{t}^{* T}-\alpha_{t}^{* N T}\right)+v_{t}, & & v_{t} \sim N\left(0, V_{t}\right), \\
\bar{q}_{t} & =\bar{q}_{t-1}+w_{1 t}, & & w_{1 t} \sim N\left(0, W_{1 t}\right), \\
\beta_{1 t} & =\beta_{1 t-1}+w_{2 t}, & & w_{2 t} \sim N\left(0, W_{2 t}\right), \\
\beta_{2 t} & =\beta_{2 t-1}+w_{3 t}, & & w_{3 t} \sim N\left(0, W_{3 t}\right) .
\end{aligned}
$$

where $\mathrm{p}$ is the $\log$ of the German CPI; $\mathrm{p}^{*}$ is the log of the US CPI; $\alpha_{t}^{T}\left(\alpha_{t}^{N T}\right)$ is the percentage change in productivity in the German tradable (nontradable) sectors represented by the $\log$ of the ratio of production to employment in the tradable (nontradable) sectors; $\alpha_{t}^{* T}\left(\alpha_{t}^{* N T}\right)$ is the percentage change in productivity in the American tradable (nontradable) sectors represented by the log of the ratio of production to employment in the tradable (nontradable) sectors.

Figure 7 shows the time plots of the annual German real exchange rate and productivity differential and the American productivity differential. The relationship between the productivity differential and the real exchange rate is not clear in the plots. Figure 8 depicts the scatter plots for the German real exchange rate and the German productivity differential. Figure 9 shows the scatter plots for the German real exchange rate and the American productivity differential. The scatter plots are not informative about the relationship between the German real exchange rate and the productivity differentials although the correlation coefficients show that they are positively related. 


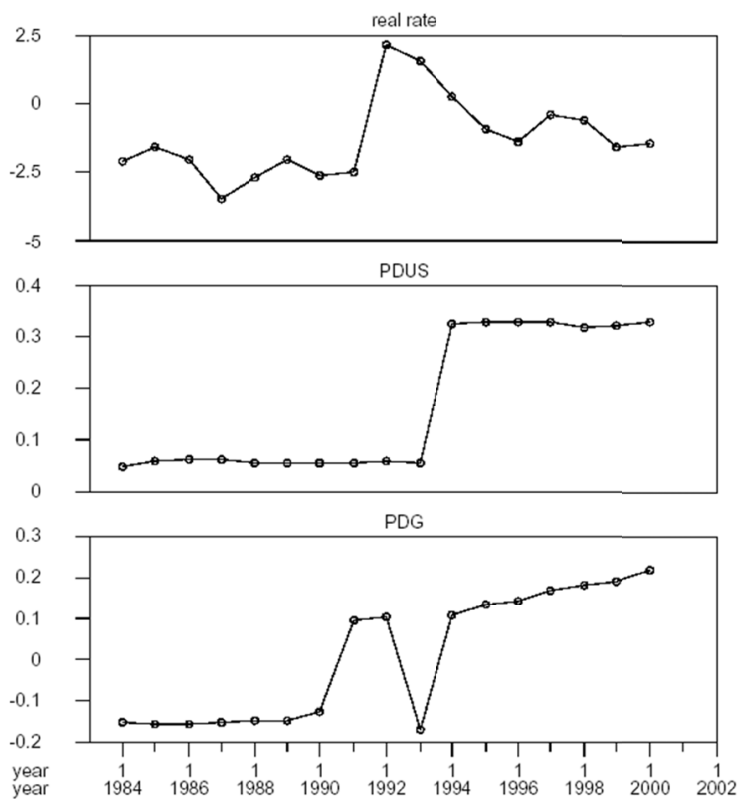

Figure 7. German annual real exchange rate and productivity differentials (1984-2000)

Note. PDUS = American productivity differential between traded and nontraded goods; PDG $=$ German productivity differential between traded and nontraded goods.

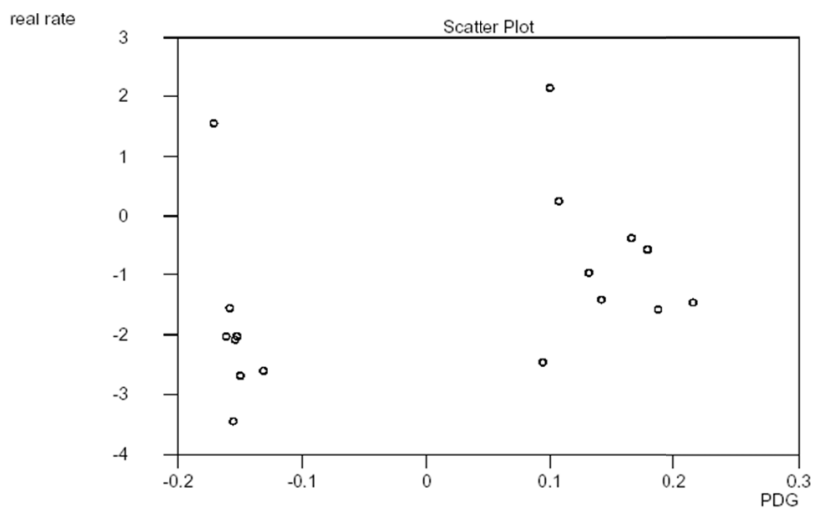

Figure 8. German real exchange rate and German productivity differential Note. Correlation coefficient $=0.327$.

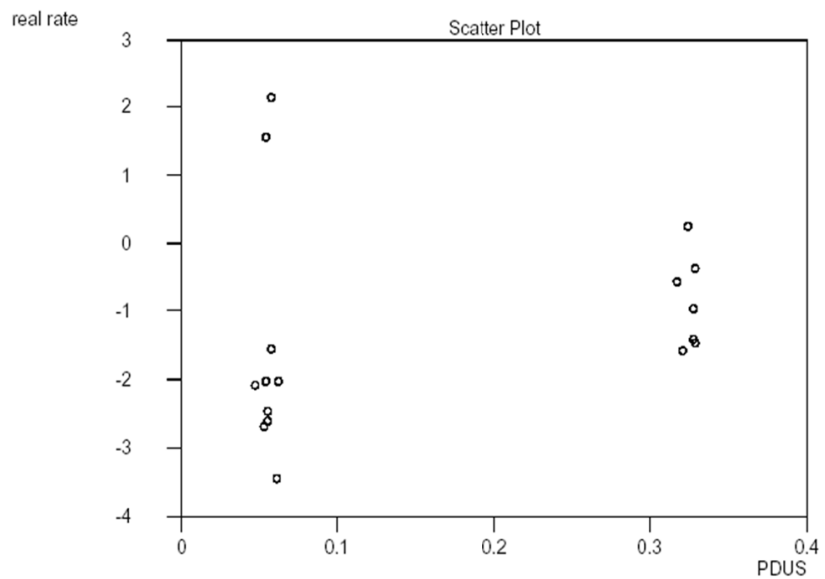

Figure 9. German real exchange rate and american productivity differential Note. Correlation coefficient $=0.22$. 
Figure 10 through Figure 12 show the results of steady analysis with a trend discount factor 0.8 and BATS level increase monitor on, which means we make use of upward shifts in the trends. The year 1992 was signaled as an outlier and ignored in the analysis. The retrospective fitted value of the German real exchange rate is relatively stable from 1984 to 1992 , followed by a sharp increase around 1992 and then a gradual decrease. This is probably due to the reunification of Germany in 1990. Figure 13 shows that there is not much autocorrelation of the residuals.

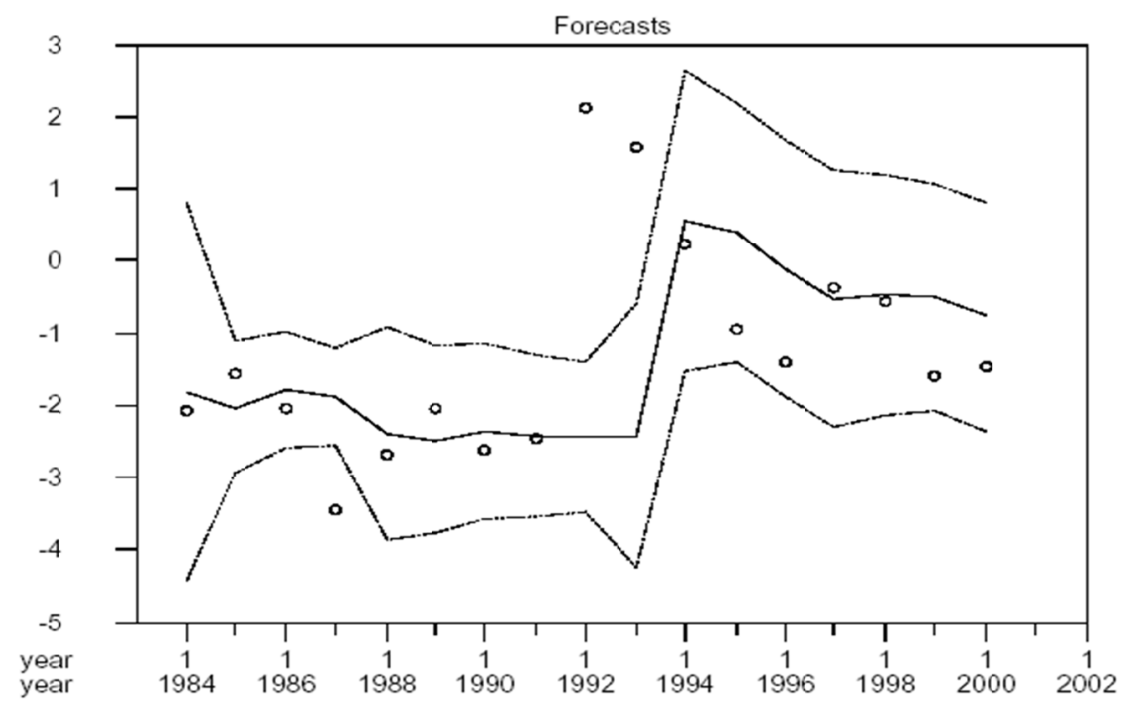

Figure 10. One-year ahead forecasts for German real exchange rate

Note. Year 1992 is ignored as an outlier.

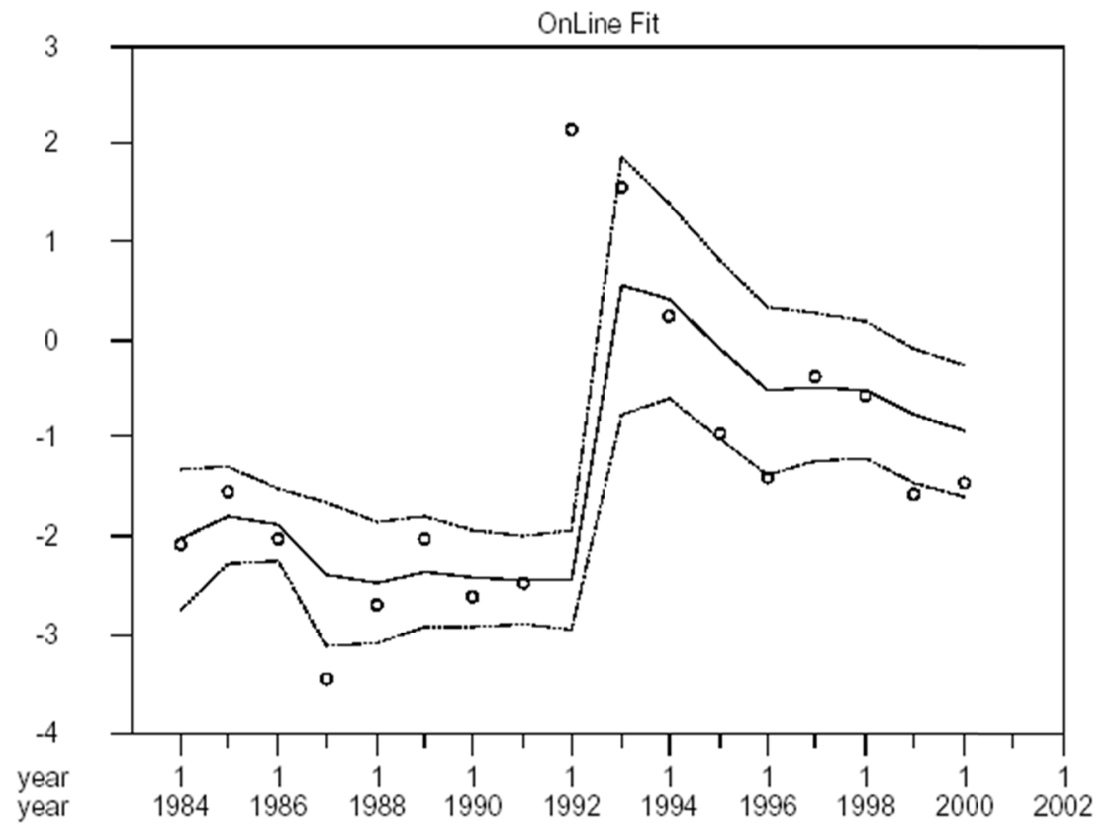

Figure 11. On-line fitted value (on-line estimated level) for annual German real exchange rate Note. Year 1992 is ignored as an outlier. 


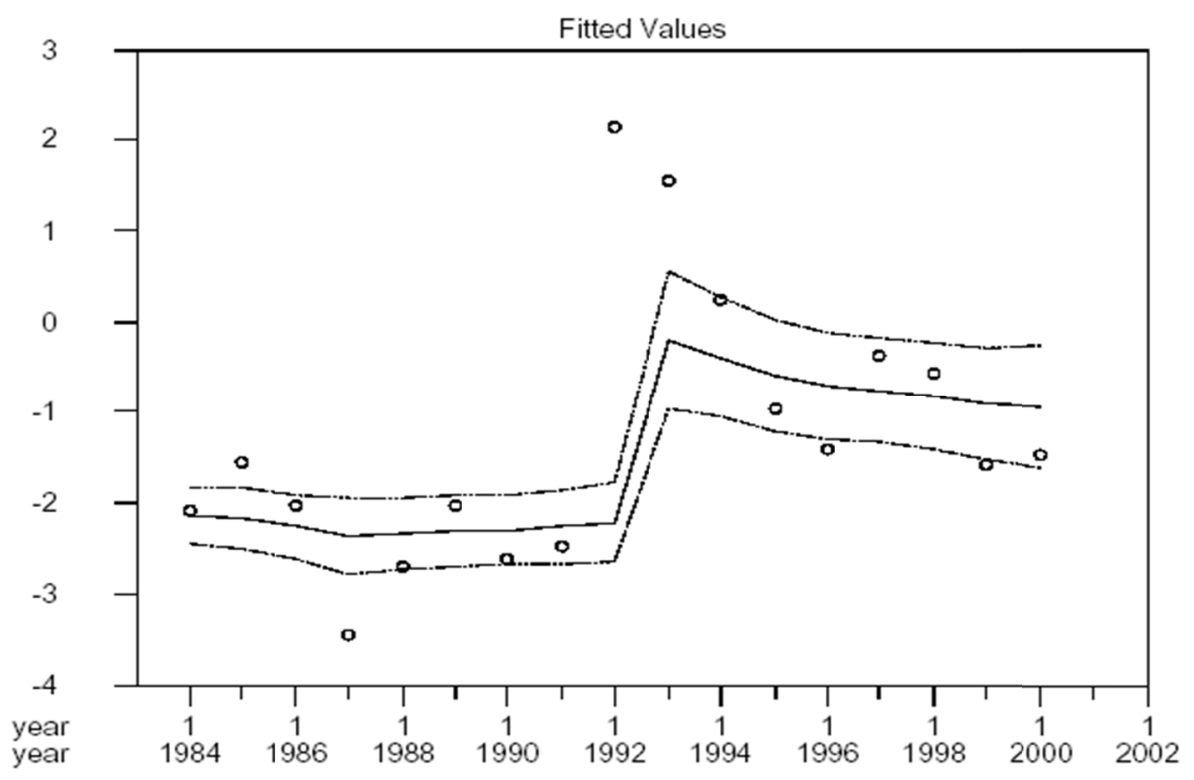

Figure 12. Retrospective fitted value for annual German real exchange rate

Note. Year 1992 is ignored as an outlier.

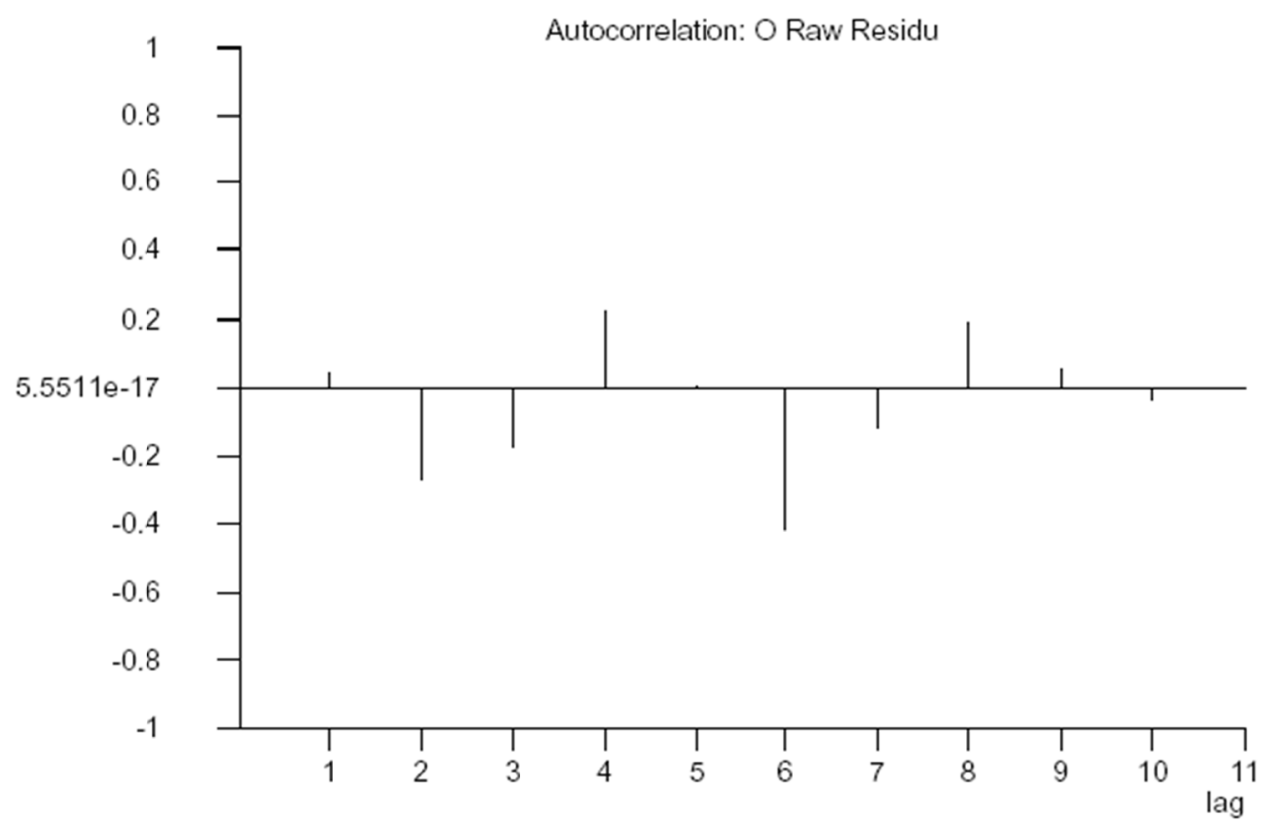

Figure 13. Autocorrelation of on-line fitted residuals

Can the productivity differentials explain the movement of the real exchange rate? Table 4 shows the forecast performance summary statistics of the regression model for several sets of discount factors. In the regression model, we need two discount factors: one for the trend and one for the regression. As we can see, the best measure at which the trend discount factor is around 1 and the regression discount factor is 0.95 . Another set of forecast performance summary statistics with intervention is reported in Table 5. Surprisingly, the measures with intervention are in general not better than those without intervention, even though the best measures are better. Note the discount factors with the best measures are both 1 . It seems that there is not much dynamic in the series and static analysis would be sufficient. This might be due to the small sample size and relatively time-invariant observations (especially when 1992 was ignored as an outlier in the analysis). 
Table 4. Forecast performance summary - Regression model

\begin{tabular}{ccccc}
\hline $\begin{array}{c}\text { Regression } \\
\text { Component Discount }\end{array}$ & 0.95 & 0.98 & 0.99 & 1.00 \\
\hline 0.90 & 319.1400 & 314.1800 & 314.2900 & 316.1300 \\
& 5.7141 & 5.9533 & 6.1510 & 6.3756 \\
0.95 & -50.9260 & -49.9760 & -49.7050 & -49.4760 \\
& 270.7000 & 237.9200 & 225.9500 & 215.3400 \\
& 5.6287 & 5.0536 & 5.2296 & 5.4768 \\
0.98 & -49.4840 & -48.9570 & -48.8790 & $-48.8420^{*}$ \\
& 227.4500 & 161.4300 & 136.7900 & 127.8000 \\
& 5.3669 & 4.3502 & 4.5688 & 4.9632 \\
1.00 & -49.3770 & -49.2230 & -49.1760 & -49.0660 \\
& 189.0300 & 89.3460 & 71.0610 & $11.0930^{*}$ \\
& 5.1121 & 3.7230 & 4.0029 & $2.1889^{*}$ \\
& -49.5790 & -49.3800 & -49.2870 & -48.8480 \\
\hline
\end{tabular}

Note. The numbers in each cell are Mean Squared Error, Mean Absolute Deviation, and Log Predictive Likihood. *, Best value for measure. Observation variance discount is 0.99 .

Table 5. Forecast performance summary with intervention - Regression model

\begin{tabular}{ccccc}
\hline $\begin{array}{c}\text { Regression } \\
\text { Component Discount }\end{array}$ & 0.95 & 0.98 & 0.99 & 1.00 \\
\hline 0.90 & 397.9400 & 381.3600 & 374.1800 & 365.8400 \\
& 7.4493 & 7.2141 & 7.1073 & 6.9789 \\
& -46.8070 & -45.0550 & -44.4790 & -43.9190 \\
0.95 & 358.3300 & 318.3100 & 298.3500 & 272.8000 \\
& 7.3787 & 7.2207 & 6.8041 & -40.7880 \\
0.98 & -43.8030 & -40.3690 & -41.2180 & 144.7200 \\
& & & & 5.2249 \\
& 314.0100 & 240.1700 & 199.4800 & -39.5360 \\
& 7.0916 & 6.3852 & 5.9349 & -40.0680 \\
& -42.0390 & -40.3960 & & $1.2389 *$ \\
& 189.0300 & 133.4700 & 105.1600 & $1.9543 *$ \\
& 5.1121 & 5.0584 & 4.6092 & $-32.2080^{*}$ \\
\hline
\end{tabular}

Note. The numbers in each cell are Mean Squared Error, Mean Absolute Deviation, and Log Predictive Likihood. *, Best value for measure. Observation variance discount is 0.99 .

Table 6. Smoothed coefficients of the regression model with intervention

\begin{tabular}{cccc}
\hline Year & $\bar{q}$ & $\beta 1$ & $\beta 2$ \\
\hline $1984-1993$ & -1.981 & -2.021 & -11.265 \\
$1994-2000$ & 1.041 & -2.330 & -4.736 \\
\hline
\end{tabular}

Note. All the coefficients are with $90 \%$ uncertainty limits that vary over time.

Figure 14 through Figure 17 show selected results from the intervention analysis with discount factors 1 for the trend and regression components, and 0.99 for the observation variance (Note 6). Table 6 reports the smoothed coefficients of the analysis. The sign of the coefficient of the German productivity differential is negative, not positive as we predicted. The sign of the $\beta 2$ is negative as the theory suggests. We can see in Figure 15 , however, that the effect of German productivity is positive before 1991 and negative thereafter. Since the coefficient of German productivity is negative during the period, the positive effect suggests that the productivity differential between tradables and nontradables is negative from 1984 to 1991. There are two possible explanations for this result. One is that the tradable sector is more labor intensive, that is, $\mu_{L N}<\mu_{L N}$, which is less likely; the other 
possibility is that nontradable sector is still more labor intensive, but the productivity growth is much faster in the non-tradable sectors during this period. Is it possible that the development of information technology has made the productivity in nontradable sectors increase more rapidly? Both scenarios, however, conflict with the assumptions of the Balassa-Samuelson effect.

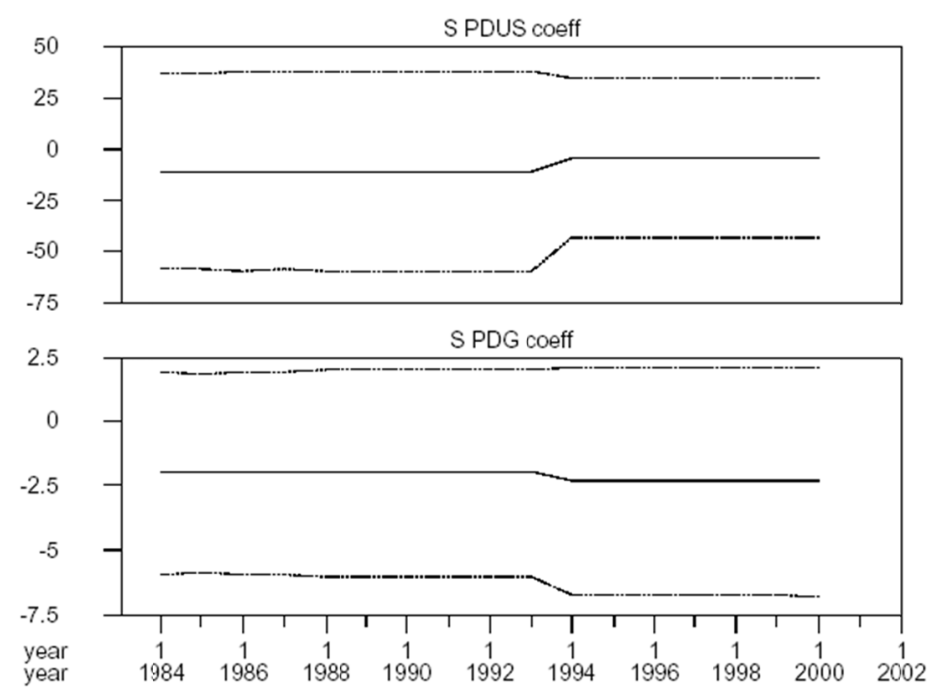

Figure 14. Smoothed coefficients of productivity differentials

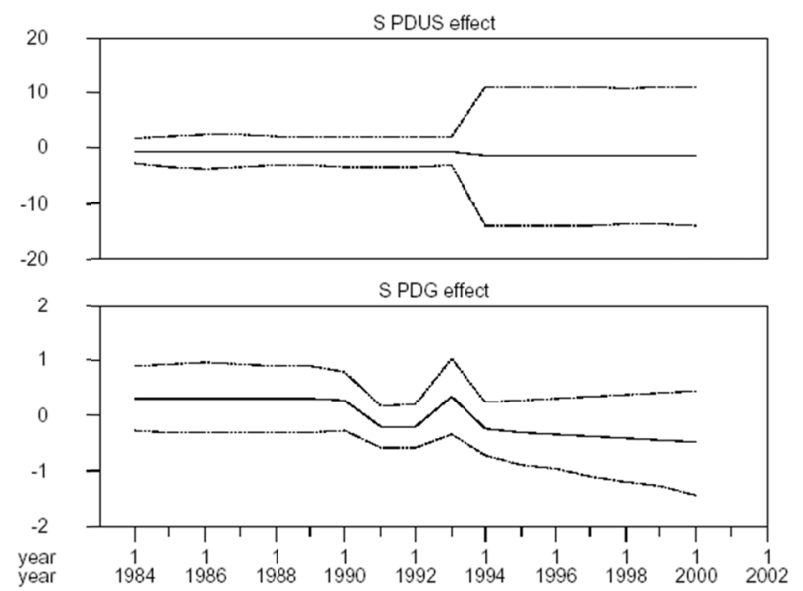

Figure 15. Smoothed effects of productivity differentials

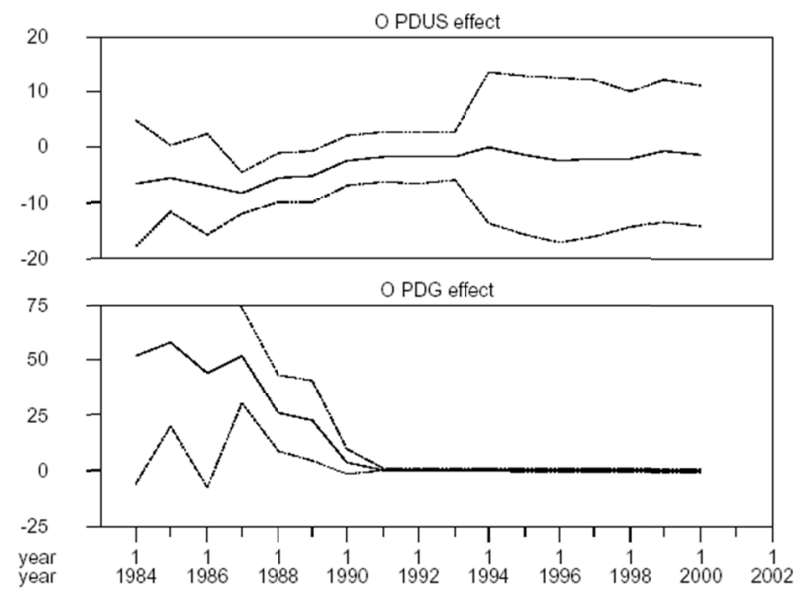

Figure 16. On-line fitted effects of productivity differentials 


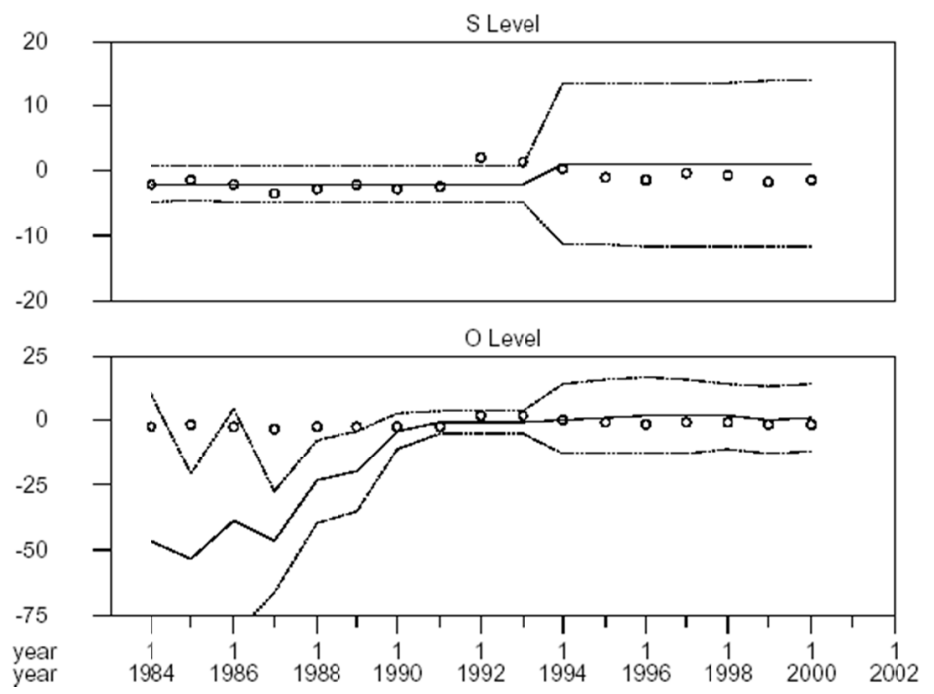

Figure 17. Smoothed and on-line estimated underlying level

\section{Conclusions}

This study uses the Bayesian dynamic linear model to examine the evolution of the German (CPI) real exchange rate with respect to the United States for the period 1974:1-2001:4, and investigate whether the Balassa-Samuelson effect explains the deviation of PPP for the years 1984-2001.

The results show that the German real exchange rate is stable during a short period but wanders away over time. This suggests that PPP does not hold in the examined period. The Balassa-Samuelson effect states that historically technological progress was faster in traded goods sectors and a rise in productivity in those sectors will bid up the wage rate in the economy and thus the prices of nontraded goods. Therefore, the real exchange rate will increase as the prices of nontraded goods go up. Although the coefficient of the German productivity differential is negative, the effect of the productivity differential is positive from 1984 to 1991. It is possible that the German tradable sector is more labor intensive, or productivity grows much faster in the non-traded goods sectors during this period. However, both projections violate the assumptions of the Balasisa-Samuelson effect.

Dynamic or time-varying Balassa-Samuelson effect was also tested. Disappointingly, the forecast measure shows that the static model would be the best choice for the years 1984-2000. However, this is not surprising because the real exchange rate series is not very time variant during that period. Moreover, when the year 1992 is ignored in the analysis, the series becomes even more stable. Therefore, the results would be very sensitive with the period selected in the study.

Although the empirical results are not ideal, the Bayesian DLM provides a method for examining the dynamics of the model, quantifies external information to the priors, and gives some hope about empirical macroeconomic study in which a small sample size is always an issue. In addition, since the Balassa-Samuelson effect is one of the supply-side forces that determine the real exchange rate, a future study could include demand-side factors in the dynamic model and could compare the significance of demand and supply factors in determining the real exchange rate.

\section{References}

Asea, P. K., \& Menzoda, E. (1994). The Balassa-Samuelson Model: A General Equilibrium Appraisal. Review of International Economics, 20, 195-220.

Bahmani-Oskooee, M., \& Rhee, H. J. (1996). Time-Series Support for Balassa's Productivity-Bias Hypothesis: Evidence from Korea. Review of International Economics, 4, 364-370. http://dx.doi.org/10.1111/j.1467-9396.1996.tb00110.x

Balassa, B. (1964). The purchasing power doctrine: a re-appraisal. Journal of Political Economy, 72, 584-596. http://dx.doi.org/10.1086/258965

Canzoneri, M. B., Cumby, R., \& Diba, B. (1999). Relative Labor Productivity and the RealExchange rate in the Long Run: Evidence for a Panel of OECD Countries. Journal of International Economics, 47(2), 245-266. http://dx.doi.org/10.1016/S0022-1996(98)00021-X 
Chang, J. (2002). Real Exchange Rate and Relative Real Wages: Balassa-Samuelson Model Revisited. Dissertation, University of Washington, 2002.

Chinn, M., \& Johnson, L. (n.d.). Real Exchange Rate levels, productivity and Demand Shocks: Evidence from of Panel of 14 Countries. IMF working paper: WP/97/66.

De Carvalho, A. (2002). Equlibrium Yen-Dollar Rate: 1976-1991. Asian Economic Journal, 16(1), 53-70. http://dx.doi.org/10.1111/1467-8381.00142

De Gregorio, J., Giovannini, A., \& Wolf, H. (1994). International Evidence on Tradables and Nontradables Inflation. European Economic Review, 38, 1225-1244. http://dx.doi.org/10.1016/0014-2921(94)90070-1

Dibooglu, S. (1996). Real Distances, Relative prices and Purchasing Power Parity. Journal of Macroeconomics, 18(1), 69-87. http://dx.doi.org/10.1016/S0164-0704(96)80004-8

Edison, H., \& Klovland, J. T. (1987). A quantitative assessment of the purchasing power parity hypothesis: evidence from Norway and the United Kingdom. Journal of Applied Econometrics, 2, 309-333. http://dx.doi.org/10.1002/jae.3950020404

Froot, K. A., \& Kenneth, R. (1991). The EMS, the EMU, and the transition to a common currency. In S. Fisher \& O. Blanchard (Eds.), NBER macroeconomics annual (pp. 269-317). MIT Press, Cambridge, MA..

Froot, K. A., \& Kenneth, R. (1995). Perspectives on PPP and Long-Run Real ExchangeRates. In G. Grossman \& K. Rogoff (Eds.), Handbook of International Economics. Elsevier Science.

Hsieh, D. A. (1982). The determination of the real exchange rate: the productivity approach. Journal of International Economics, 12, 355-362. http://dx.doi.org/10.1016/0022-1996(82)90045-9

Kakkar, V., \& Ogaki, M. (1999). Real Exchange Rates and Nontradables: A Relative Price Approach. Journal of Empirical Finance, 6, 193-215. http://dx.doi.org/10.1016/S0927-5398(98)00016-4

Koedijk, K. G., Schotman, P. C., \& Van Dijk, M. A. (1998). The Re-emergence of PPP inthe 1990s. Journal of International Money and Finance, 17(1), 51-61. http://dx.doi.org/10.1016/S0261-5606(97)98051-7

Marston, R. (1987). Real exchange rate and productivity growth in the United States and Japan. In S. Arndt \& J. D. Richardson (Eds.), Real-financial linkages among open economies. MIT Press, Cambridge, MA.

Pole, A., Mike, W., \& Jeff, H. (1994). Applied Bayesian Forecasts and Time Series Analysis. Champman \& Hall. http://dx.doi.org/10.1007/978-1-4899-3432-1

Samuleson, P. (1964). Theoretical notes on trade problems. Review of Economics and Statistics, 46, $145-164$. http://dx.doi.org/10.2307/1928178

Strauss, J., \& Mark, E. F. (1996). The Role of Nontraded and Traded wages in the Productivity Differential Model. Southern Economic Journal, 63(2), 327-338. http://dx.doi.org/10.2307/1061171

Weber, A. A. (1997). Sources of Purchasing Power Disparities between the G3 Economies. Journal of the Japanese and International Economics, 11(4), 548-583. http://dx.doi.org/10.1006/jjie.1997.0395

\section{Notes}

Note 1. The 14 countries are Australia, Belgium, Canada, Denmark, Finland, France, (Western) Germany, Italy, Japan, the Netherlands, Norway, Sweden, the United Kingdom, and the United States.

Note 2. (1) agriculture, (2) mining, (3) food, beverages, and tobacco, (3) textiles, (5) wood and wood products, (6) paper, printing, and publishing, (7) chemicals, (8) nonmetallic mineral products, (9) basic metal products, (10) machinery equipment, (11) other manufactured products, (12) electricity, gas and water, (13) construction, (14) wholesale and retail trade, (15) restaurants, hotels, (16) transport, storage, and communications, (17) finance, insurance, (18) real estate, (19) community, social, and personal services, and (20) government services.

Note 3. All data sets are from the OECD Statistical Compendium, 2002-2.

Note 4. BATS refers to the Bayesian analysis of time series, software developed by Andy and Chris Pole in 1994 in the book Applied Bayesian Forecasting and Time Series Analysis by Andy Pole, Mike West and Jeff Harrison.

Note 5 . The on-line estimated level is identical to the fitted value because the steady model is composed only of the single factor, the estimated value.

Note 6. Analyses with discount factors less than one have similar results, with or without intervention. 


\section{Copyrights}

Copyright for this article is retained by the author(s), with first publication rights granted to the journal.

This is an open-access article distributed under the terms and conditions of the Creative Commons Attribution license (http://creativecommons.org/licenses/by/3.0/). 